Revista Verde de Agroecologia e Desenvolvimento Sustentável

http://www.gvaa.com.br/revista/index.php/RVADS

ARTIGO CIENTÍFICO

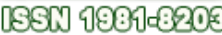

DOI: http://dx.doi.org/10.18378/rvads.v10i3.3692

\title{
Crescimento de porta-enxerto de goiabeira sob águas salinizadas e doses de nitrogênio"
}

\section{Guava rootstocks growth in salted water and nitrogen levels}

\author{
Leandro de Pádua Souza ${ }^{1}$; Reginaldo Gomes Nobre ${ }^{2}$; Evandro Manoel da Silva ${ }^{3}$; Francisco Wesley Alves Pinheiro ${ }^{4}$; \\ Luana Lucas de Sá Almeida
}

\begin{abstract}
Resumo: A salinidade da água de irrigação pode afetar a exploração de cultivos principalmente nas regiões áridas e semiáridas, entretanto, algumas alternativas podem favorecer a exploração agrícola nestas condições. Desse modo, objetivouse com este trabalho, avaliar a interação entre adubação nitrogenada e a salinidade da água de irrigação sob o crescimento de porta-enxerto de goiabeira 'Crioula' em condição de semiárido do nordeste do Brasil. O experimento foi conduzido em tubetes sob condições de ambiente protegido no CCTA/UFCG. Utilizou-se o delineamento experimental em blocos casualizados, com os tratamentos dispostos em esquema fatorial $5 \times 4$, correspondentes a cinco níveis de condutividade elétrica da água - CEa $\left(0,3 ; 1,1 ; 1,9 ; 2,7\right.$ e $\left.3,5 \mathrm{dS} \mathrm{m}^{-1}\right)$ e quatro doses de nitrogênio $(70,100,130$ e $160 \%$ de $\mathrm{N}$ da dose recomendada para a cultura), com 4 repetições e 5 plantas por parcela. A dose de $70 \%$ de $\mathrm{N}\left(541,1 \mathrm{mg} \mathrm{de} \mathrm{N} \mathrm{dm}^{-1}\right.$ de solo) proporciona maior diâmetro de caule de porta-enxerto de goiabeira crioula aos 70 e 145 dias após a emergência (DAE), sobre a área foliar e altura de planta aos 145 DAE e na taxa de crescimento absoluto diâmetro do caule dos 25 a 145 DAE. A irrigação com água cuja salinidade era acima de $0,3 \mathrm{dS} \mathrm{m}^{-1}$ afeta positivamente a razão de área foliar e de forma negativa, o número de folhas, a área foliar e o diâmetro do caule. Houve interação significativa entre os fatores adubação nitrogenada e salinidade da água de irrigação apenas para a variável número de folhas aos 145 DAE.
\end{abstract}

Palavras-chaves: Psidium guajava L., Salinidade, Adubo.

Abstract: Salt stress suffered by plants due to concentration of irrigation water salts reduces the ability of exploitation of cultures especially in arid and semiarid regions. Thus, the aim of this study was to evaluate the effect of salinity of irrigation water on the growth of rootstock of guava 'Crioula' associated with increasing doses of nitrogen fertilizer. The experiment was conducted in plastic pots under greenhouse conditions in the CCTA / UFCG. We used the experimental randomized block design, with the treatments in a factorial $5 \times 4$, corresponding to five levels of electrical conductivity of the water - CEa $(0.3$; $1.1 ; 1.9 ; 2.7$ and $\left.3.5 \mathrm{dS} \mathrm{m}^{-1}\right)$ and four nitrogen rates $(70,100,130$ and $160 \%$ of the recommended dose $\mathrm{N}$ for guava cultivation seedlings cv. Paluma) with 4 replications and 5 plants per plot. The dose of $70 \%$ of $\mathrm{N}-\left(541.1 \mathrm{mg} \mathrm{N} \mathrm{dm}^{-1}\right.$ of soil $)$ provides greater production plant leaf area, height $145 \mathrm{DAE}$, but to stem diameter was significant in both periods studied the rootstock guava cv. Crioula. Irrigation $\mathrm{CEa}$ above $0.3 \mathrm{dS} \mathrm{m}^{-1}$ negatively affect the number of leaves, leaf area, stem diameter, leaf area ratio and absolute growth rate of stem diameter. There was interaction between the factors salinity of irrigation water and nitrogen fertilization for variable number of leaves at 145 DAE rootstock of guava "Crioula".

Key words: Psidium guajava L., salinity, fertilizer

\footnotetext{
*Autor para correspondência

Recebido para publicação em 05/07/2015; aprovado em 10/09/2015

*Trabalho faz parte da dissertação do primeiro autor, financiado pelo CNPq edital Universal.

${ }^{1}$ Eng. Agrônomo, Pós-graduando em Horticultura Tropical, Centro de Ciências e Tecnologia Agroalimentar, Universidade Federal de Campina Grande, CEP 58015-570 Pombal, PB, Fone (87) 96373266. E-mail: engenheiropadua@ hotmail.com,

${ }^{2}$ Prof. Doutor Adjunto III CCTA/ UAGRA/UFCG, Pombal, PB. E-mail: rgomesnobre@pq.cnpq.br;

${ }^{3}$ Eng. Agrônomo, Mestre em Horticultura Tropical. Pombal, PB. E-mail: evandroagroman@hotmail.com

${ }^{4}$ Graduando em Agronomia, CCTA/UFCG, Pombal, PB. E-mail: wesley.ce@ hotmail.com;

${ }^{5}$ Eng. Agrônoma, Pós-graduanda em Horticultura Tropical CCTA/ UFCG, Pombal, PB. E-mail: luana_lucas_15@hotmail.com
} 


\section{INTRODUÇÃO}

A goiabeira (Psidiumguajava L.) pertencente à família das Myrtaceas, originária das regiões tropicais americanas, encontra-se distribuída naturalmente em todo território brasileiro, onde produzem frutos de elevado valor nutritivo e grande aceitação no mercado, tanto para o consumo in natura como para as atividades agroindustriais, que a utilizam para o processamento de diversos produtos (OLIVEIRA et al., 2015).

De acordo com IBGE (2012) entre as regiões brasileiras mais produtivas, destacam-se o Sudeste e o Nordeste representado $46,6 \%$ e $42,2 \%$, respectivamente, da produção Nacional, com produção de 345,3 mil toneladas numa área colhida de 15,2 mil hectares.

Assim como outras fruteiras de importância econômica, é amplamente cultivada em áreas irrigadas no semiárido, destacando-se como de grande valor econômico para o Nordeste brasileiro (GURGEL et al., 2007; FREITAS e ALVES, 2008).

A salinização dos solos pode ser tanto de origem natural como antropogênica. Entretanto, nessas áreas cultivadas, ela decorre, frequentemente, da ação do homem através da adoção de práticas agrícolas inadequadas que contribuem para o seu agravamento. Embora a ocorrência de solos salinos possa ser verificada nas mais distintas condições ambientais, este problema é mais frequente em regiões áridas e semiáridas (FERNANDES et al., 2010).

O Nordeste brasileiro apresenta condições climáticas bem específicas, como alta taxa de evaporação e precipitações irregulares causando a escassez de água na maior parte dos meses do ano (QUEIROZ et al., 2010).

Segundo Neves et al. (2009) na região semiárida brasileira é comum a utilização de águas com alta concentração de sais, sobretudo de sódio, na irrigação e isso tem comprometido a qualidade desse recurso e do próprio solo, e em consequência a agricultura é afetada.

Os efeitos da salinidade da água de irrigação sobre as plantas se refletem em alterações no potencial osmótico, na toxidade dos íons e no desequilíbrio nutricional das plantas (FERREIRA et al., 2007).

Em termos de diversidade na tolerância à salinidade, pode-se classificar as plantas como halófitas e glicófitas (WILLADINO; CAMARA, 2010). As plantas halófitas apresentam mecanismos de exclusão de $\mathrm{Na}^{+}$e $\mathrm{Cl}^{-}$em estruturas morfológicas como glândulas secretoras e pêlos vesiculares (FERNANDES et al., 2010). As glicófitas são a maioria das plantas cultivadas, inclusive a goiabeira, que são incapazes de se desenvolver em ambientes com elevadas concentrações salinas, sofrendo decréscimos de turgor e redução no crescimento quando a salinidade supera $10 \mathrm{Mm}$ (WILLADINO; CAMARA, 2004).

A formação de mudas de goiabeira, na região semiárida do Nordeste, onde as águas nem sempre são de boa qualidade, está na dependência do uso de técnicas que viabilizem o manejo do solo e da água com teor elevado de sais (CAVALCANTE et al., 2007). Estudos têm demonstrado que o incremento da dosagem de nitrogênio pode promover melhor eficiência na produção de mudas de goiabeira (FRANCO et al., 2007; DIAS et al., 2012).
Desse modo, objetivou-se com este trabalho, avaliar a interação entre adubação nitrogenada e a salinidade da água de irrigação sob o crescimento de porta-enxerto de goiabeira 'Crioula'.

\section{MATERIAL E MÉTODOS}

O trabalho foi desenvolvido em ambiente protegido (casa de vegetação) do Centro de Ciências e Tecnologia Agroalimentar da Universidade Federal de Campina Grande (CCTA/UFCG), Pombal-PB, cujas coordenadas geográficas locais de referência são 6 $6^{\circ} 48^{\prime} 16^{\prime \prime} \mathrm{S}, 37^{\circ} 49^{\prime} 15^{\prime}$ O e altitude média de $144 \mathrm{~m}$.

Utilizou-se o delineamento experimental em blocos casualizados, em esquema fatorial $5 \times 4$, cujos tratamentos constaram de cinco níveis de condutividade elétrica da água - $\operatorname{CEa}\left(0,3 ; 1,1 ; 1,9 ; 2,7\right.$ e $\left.3,5 \mathrm{dS} \mathrm{m}^{-1}\right)$ e quatro doses de nitrogênio $(70,100,130$ e $160 \%$ de $\mathrm{N}$ da dose recomendada para produção de mudas de goiabeira) com 4 repetições e 5 plantas por parcela. A dose referente a $100 \%$ correspondeu a $773 \mathrm{mg} \mathrm{de} \mathrm{N} \mathrm{dm}^{-1}$ de solo, conforme recomendação de Dias et al. (2012).

As águas de diferentes salinidades foram obtidas mediante a adição do cloreto de sódio $(\mathrm{NaCl})$, de cálcio $\left(\mathrm{CaCl}_{2} \cdot 2 \mathrm{H}_{2} \mathrm{O}\right)$ e magnésio $\left(\mathrm{MgCl}_{2} \cdot 6 \mathrm{H}_{2} \mathrm{O}\right)$, na proporção de $7: 2: 1$, relação esta predominante nas principais fontes de água disponíveis para irrigação no Nordeste brasileiro (MEDEIROS, 1992), obedecendo-se a relação entre CEa e a concentração dos sais $\left(\mathrm{mmol}_{\mathrm{c}} \mathrm{L}^{-1}=\mathrm{CE} \times 10\right)$ (RHOADES et al., 2000).

Utilizou-se a goiabeira "Crioula" por se tratar de genótipo de fácil propagação, com tolerância a pragas e doenças, principalmente à ferrugem (Puccinia psidii Wint.) e por ser uma das mais cultivadas no Nordeste Brasileiro (MENDONÇA et al., 2011).

Usou-se para a condução das plantas, tubetes plásticos de $19 \mathrm{~cm}$ de altura e $6,3 \mathrm{~cm}$ de diâmetro, capacidade $288 \mathrm{~cm}$ 3 , e abertura na parte inferior para permitir livre drenagem. Estes recipientes foram dispostos em bandejas com capacidade para 54 tubetes, apoiadas em bancadas metálicas (cantoneiras), a uma altura de $0,8 \mathrm{~m}$ do solo.

No preenchimento dos tubetes foi utilizado substrato composto de Neossolo flúvico + areia + esterco bovino curtido respectivamente, na proporção de 82,15 e $3 \%$, cujas características físicas e químicas (Tabela 1), foram analisadas no Laboratório de Solos e Planta do CCTA/UFCG, e obtidas conforme Claessen (1997).

O semeio foi realizado em 18 de março de 2014, usando-se quatro sementes por tubete, e semeadas na profundidade de $1,0 \mathrm{~cm}$. Após as plântulas apresentarem dois pares de folhas verdadeiras totalmente expandidas, realizouse o desbaste, deixando-se apenas uma plântula por tubete, a de melhor vigor, além disso, foram realizados outros tratos culturais, como capinas manuais e escarificação superficial do substrato. Antes do semeio o solo foi posto em capacidade de campo usando água (sistema de abastecimento local) de baixa salinidade $\left(0,3 \mathrm{dS} \mathrm{m}^{-1}\right)$. 
Tabela 1. Características físicas e químicas do substrato utilizado no experimento

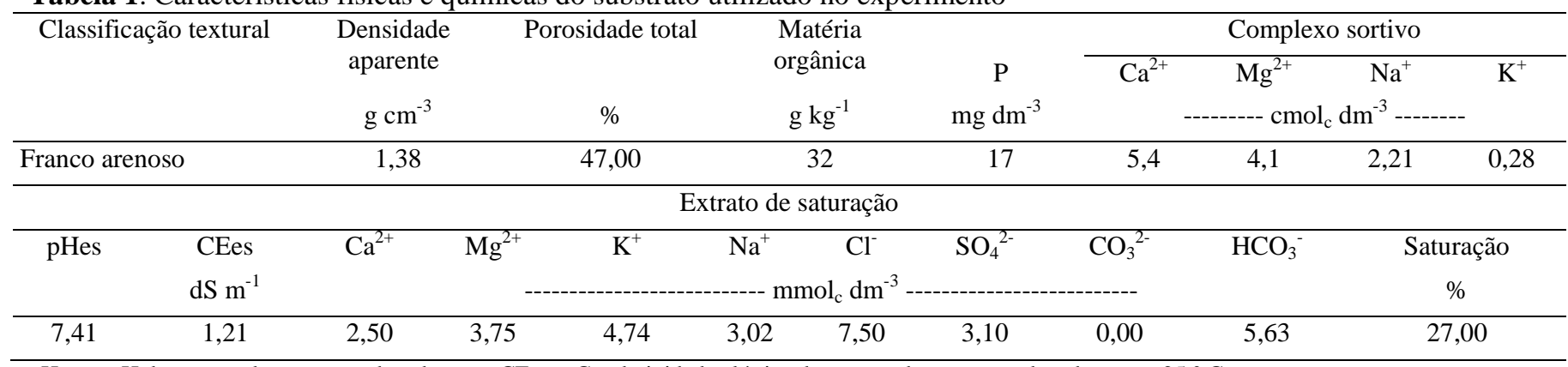

pHes $=$ pH do extrato de saturação do substrato; CEes = Condutividade elétrica do extrato de saturação do substrato a $25^{\circ} \mathrm{C}$

A aplicação dos tratamentos teve início aos 25 dias após a emergência de plântulas (DAE). As irrigações com águas salinas foram feitas, conforme o tratamento, com base na necessidade hídrica da planta, pelo processo de lisimetria de drenagem, sendo aplicado diariamente o volume retido no tubete, determinado pela diferença entre o volume aplicado e volume drenado da irrigação anterior. As irrigações foram feitas duas vezes ao dia, sendo no início da manhã e final da tarde. Aplicou-se a cada quinze dias, uma fração de lixiviação de $15 \%$ com base no volume aplicado neste período, de modo a reduzir a salinidade do extrato de saturação do substrato.

A adubação nitrogenada iniciou-se aos 25 DAE, e foi dividida em 14 aplicações em partes iguais, realizadas semanalmente, onde se utilizou como fonte de nitrogênio a ureia ( $45 \%$ de $\mathrm{N}$ ), com aplicações realizadas via fertirrigação com água de condutividade elétrica de $0,3 \mathrm{dS} \mathrm{m}^{-1}$ para todos os tratamentos.

$\mathrm{Na}$ avaliação do crescimento de porta-enxerto de goiabeira cv. 'Crioula' fez-se aos 70 e 145 DAE a avaliação do diâmetro de caule (DC), altura de planta (AP), número de folhas (NF), área foliar (AF), além da razão de área foliar (RAF) aos 190 DAE. E, no período compreendido entre 25145 DAE determinou-se as taxas de crescimento absoluto (TCAdc) e relativo do diâmetro do caule (TCRdc) de portaenxerto de goiabeira.

O DC foi medido a $5 \mathrm{~cm}$ do colo da planta. A AP foi determinada mensurando-se a distancia da superfície do solo até a inserção do meristema apical. $\mathrm{O} N F$ foi feito por contagem simples, considerando as que estavam com o limbo foliar totalmente aberto. A AF foi obtida de acordo com Lima et al. (2012) conforme Eq. 1:

$$
A=0,3205 \times C^{2,0412}(1)
$$

Sendo:

$\mathrm{AF}$ - área foliar $\left(\mathrm{cm}^{2}\right)$;

C - comprimento da nervura principal da folha $(\mathrm{cm})$.

A TCAdc e TCRdc foram determinadas de acordo com metodologia descrita por Benincasa (2003), conforme as Eq. 2 e 3.

$$
\begin{aligned}
& \text { TCAdc }=\frac{\left(\mathrm{DC}_{2}-\mathrm{DC}_{1}\right)}{\left(\mathrm{t}_{2}-\mathrm{t}_{1}\right)} \quad \text { Eq. } 2 \\
& \text { TCRdc }=\frac{\left(\operatorname{lnDC}_{2}-\operatorname{lnDC_{1})}\right.}{\left(\mathrm{t}_{2}-\mathrm{t}_{1}\right)} \quad \mathrm{Eq} .3
\end{aligned}
$$

Onde:

TCAdc $=$ taxa de crescimento absoluto do diâmetro do caule $\left(\mathrm{mm} \mathrm{dia}{ }^{-1}\right)$,

TCRdc $=$ Taxa de crescimento relativo do diâmetro do caule $\left(\mathrm{mm} \mathrm{mm} \mathrm{mia}^{-1}\right)$,

AP1 = altura de planta $(\mathrm{cm})$ no tempo $t_{1}$,

$\mathrm{AP}_{2}=$ altura de planta $(\mathrm{cm})$ no tempo $\mathrm{t}_{2}$,

$\mathrm{DC}_{1}=$ diâmetro do caule $(\mathrm{mm})$ no tempo $\mathrm{t}_{1}$,

$\mathrm{DC}_{1}=$ diâmetro do caule $(\mathrm{mm})$ no tempo $\mathrm{t}_{2}$,

$\ln =$ logaritmo natural.

Os dados obtidos foram avaliados mediante análise de variância pelo teste $F$ em nível de 0,05 e 0,01 de probabilidade e nos casos de significância, realizou-se análise de regressão utilizando do software estatístico SISVAR ESAL.

\section{RESULTADOS E DISCUSSÃO}

Conforme o resumo da análise de variância (Tabela 2) observa-se que houve efeito significativo dos níveis salino da água de irrigação sobre diâmetro de caule, altura de plantas, número de folhas e área foliar aos 70 e 145 dias após a emergência. Referente ao fator adubação nitrogenada verifica-se efeito significativo sobre DC, em ambas as datas e AP, NF e AF apenas aos 145 DAE. Constatou-se interação significativa entre os fatores salinidade da água de irrigação $\mathrm{x}$ doses de nitrogênio ( $\mathrm{S} \times \mathrm{DN}$ ) apenas sobre o número de folhas aos 145 DAE. 
Tabela 2: Resumo da análise de variância para diâmetro de caule (DC), altura de plantas (AP), número de folhas (NF) e área foliar (AF) de porta-enxerto de goiabeira "Crioula" irrigada com águas salinizadas e sob adubação nitrogenada, aos 70 e 145 dias após a emergência - DAE.

\begin{tabular}{|c|c|c|c|c|c|c|c|c|c|}
\hline \multirow{3}{*}{$\begin{array}{l}\text { Fonte de } \\
\text { variação }\end{array}$} & \multicolumn{9}{|c|}{ Quadrado médio } \\
\hline & \multirow[t]{2}{*}{ GL } & \multicolumn{2}{|c|}{$\mathrm{DC}$} & \multicolumn{2}{|c|}{$\mathrm{AP}$} & \multicolumn{2}{|c|}{$\mathrm{NF}$} & \multicolumn{2}{|c|}{$\mathrm{AF}$} \\
\hline & & 70 & 145 & 70 & 145 & 70 & 145 & 70 & 145 \\
\hline Salinidades (S) & 4 & $0,071^{* *}$ & $0,357^{* *}$ & $20,460^{* *}$ & $19,02^{* *}$ & $11,820^{* * *}$ & $30,665^{* *}$ & $909,61^{*}$ & $3595,049^{*}$ \\
\hline Linear & 1 & $0,021^{* *}$ & $1,296^{* *}$ & $80,514^{* *}$ & $53,015^{* *}$ & $43,576^{* *}$ & $106,929^{* *}$ & $3163,684^{* *}$ & $12395,328^{* *}$ \\
\hline Quadrática & 1 & $0,054^{\mathrm{ns}}$ & $0,008^{\mathrm{ns}}$ & $0,697^{\mathrm{ns}}$ & $17,887^{\mathrm{ns}}$ & $3,376^{\text {ns }}$ & $2,121^{\mathrm{ns}}$ & $172,604^{\mathrm{ns}}$ & $797,959^{\mathrm{ns}}$ \\
\hline $\begin{array}{l}\text { Doses de } \mathrm{N} \\
(\mathrm{DN})\end{array}$ & 12 & $0,051^{*}$ & $0,708^{* *}$ & $5,079^{\mathrm{ns}}$ & $98,007^{* *}$ & $2,061^{\mathrm{ns}}$ & $79,564^{* *}$ & $407,723^{\mathrm{ns}}$ & $21764,813^{* *}$ \\
\hline Linear & 1 & $0,116^{* *}$ & $2,067^{* *}$ & $13,987^{* *}$ & $289,170^{* * *}$ & $4,515^{\mathrm{ns}}$ & $237,006^{* *}$ & $1182,36^{*}$ & $65144,649^{* *}$ \\
\hline Quadrática & 1 & $0,034^{\mathrm{ns}}$ & $0,0004^{\mathrm{ns}}$ & $0,924^{\mathrm{ns}}$ & $2,556^{\mathrm{ns}}$ & $1,1653^{\mathrm{ns}}$ & $0,036^{\mathrm{ns}}$ & $15,744^{\mathrm{ns}}$ & $148,757^{\mathrm{ns}}$ \\
\hline Interação $S * D N$ & 12 & $0,026^{\mathrm{ns}}$ & $0,037^{\mathrm{ns}}$ & $2,489^{\text {ns }}$ & $9,499^{\text {ns }}$ & $1,709^{\text {ns }}$ & $6,821^{*}$ & $464,537^{\mathrm{ns}}$ & $1240,998^{\mathrm{ns}}$ \\
\hline BLOCO & 3 & $0,027^{\text {ns }}$ & $0,003^{\text {ns }}$ & $1,968^{\text {ns }}$ & $4,214^{\mathrm{ns}}$ & $2,161^{\mathrm{ns}}$ & $4,382^{\mathrm{ns}}$ & $332,816^{\text {ns }}$ & $1486,71^{\text {ns }}$ \\
\hline CV (\%) & & 5,54 & 6,41 & 11,51 & 8,77 & 16,93 & 15,78 & 19,07 & 19,04 \\
\hline
\end{tabular}

$\mathrm{ns}, * *, *$ respectivamente não significativos, significativo a p $<0,01$ e p $<0,05$;

O aumento da condutividade elétrica da água de irrigação afetou de forma linear e decrescente o diâmetro do caule da goiabeira Crioula e através das equações de regressão (Figura 1A) observa-se, redução do DC de 1,92\% e $3,74 \%$ (70 e 145 DAE, respectivamente) por aumento unitário da CEa, ou seja, as plantas submetidas a irrigação com CEa de $3,5 \mathrm{dS} \mathrm{m}^{-1}$ tiveram decréscimos de $6,14 \%$ aos 70 DAE e $11,96 \%$ aos 145 DAE em comparação com as plantas submetidas a salinidade de $0,3 \mathrm{dS} \mathrm{m}^{-1}$. A salinidade da água de irrigação afeta negativamente o crescimento das plantas, devido ao efeito especifico dos íons e efeito osmótico, retardando a expansão e a divisão celular (MUNNS 2005), onde denota-se que a redução do DC tenha ocorrido m função destes fatores. Cavalcante et al., (2007) também verificaram decréscimos no diâmetro do caule de goiabeira em função do incremento de sais na água de irrigação.

Para o fator doses de nitrogênio, verifica-se pelas equações de regressão para DC (Figura 1B) diminuições de $1,2 \%$ aos 70 DAE e $4,20 \%$ aos 145 DAE por aumento de $30 \%$ das doses de $\mathrm{N}$, proporcionando declínio de $0,10 \mathrm{~mm}(3,60 \%)$ e $0,43 \mathrm{~mm}(12,60 \%)$ no DC das plantas que receberam a dose de $160 \%$ de $\mathrm{N}\left(1237 \mathrm{mg} \mathrm{de} \mathrm{N} \mathrm{dm}^{-3}\right)$ em comparação as que receberam $70 \%$ de $\mathrm{N}$ aos $70\left(541 \mathrm{mg} \mathrm{dm}^{-3}\right)$ e 145 DAE respectivamente. Dias et al. (2012) avaliando os efeitos de diferentes doses de nitrogênio $\left(0 ; 552 ; 823\right.$ e $1104 \mathrm{mg} \mathrm{N} \mathrm{dm}^{-}$ ${ }^{3}$ ) no crescimento de mudas de goiabeira, constataram que a

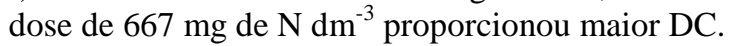

Figura 1: Diâmetro do caule - DC de porta-enxerto de goiabeira em função da salinidade da água de irrigação - CEa (A) e doses de nitrogênio (B) aos 75 e 145 dias após a emergência - DAE.

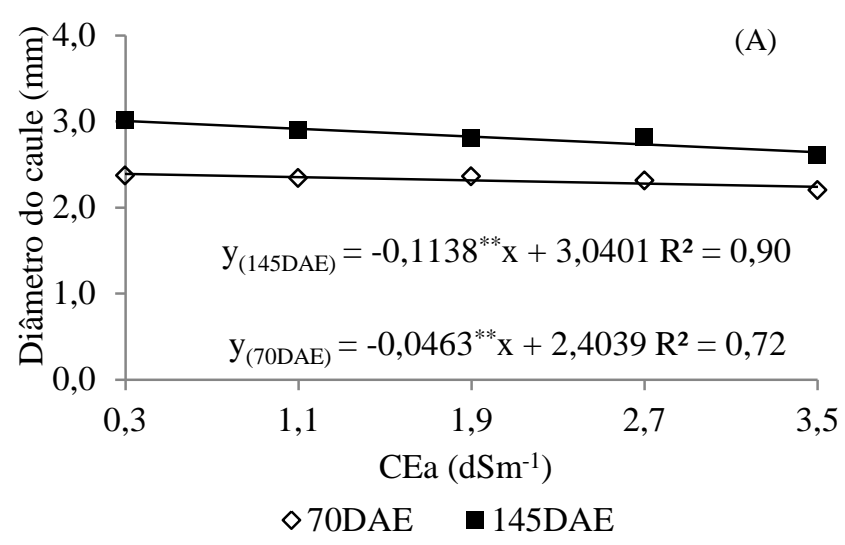

O aumento gradual da salinidade na água de irrigação causou reduções também sobre a altura de planta aos 70 e 145 DAE, e segundo equações de regressão (Figura 2A) ocorreu perdas lineares por aumento unitário de 6,38\% (70 DAE) e $2,67 \%$ (145 DAE), equivalente a $2,84 \mathrm{~cm}$ e $2,29 \mathrm{~cm}$ nas plantas irrigadas com CEa de $3,5 \mathrm{dS} \mathrm{m}^{-1}$ em relação as plantas que receberam água de condutividade menor $\left(0,3 \mathrm{dS} \mathrm{m}^{-1}\right)$. Segundo Ashraf e Harris (2004) a redução na absorção da água devido ao estresse salino, causa redução na turgescência

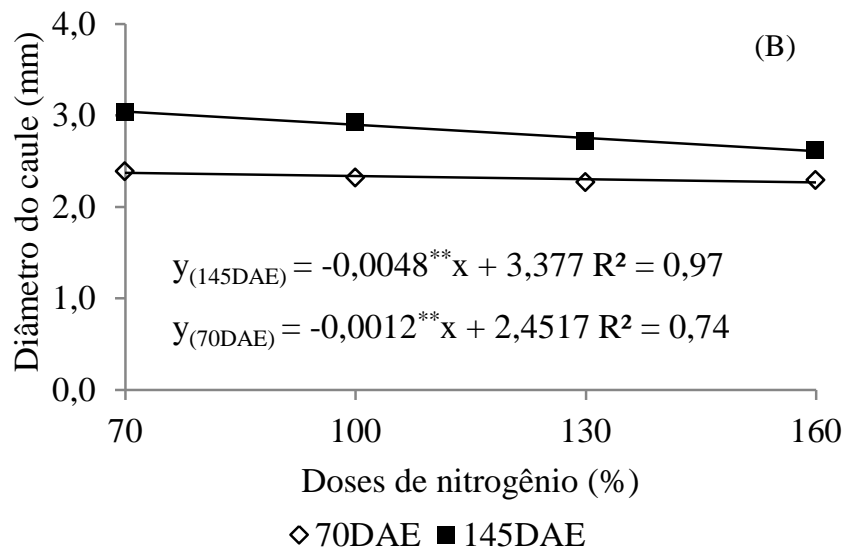

celular, afetando divisão e as taxas de alongamento e por consequência, o crescimento das plantas é prejudicado.

Analisando o efeito das doses de $\mathrm{N}$ sobre altura de planta e área folia da goiabeira Crioula, constata-se através das equações de regressão (Figura 2B e 4B) comportamento linear e decrescente, havendo diminuição na $\mathrm{AP}$ e $\mathrm{AF}$ de $5,10 \%$ e $9,56 \%$, respectivamente, por aumento de $30 \%$ das doses de $\mathrm{N}$, ou seja, as plantas submetidas à adubação de $160 \%$ de $\mathrm{N}\left(1237 \mathrm{mg} \mathrm{de}^{\mathrm{N} \mathrm{dm}}{ }^{-3}\right)$ sofreram uma redução de $15,30 \%$ (AP) e $27,90 \%$ (AF) em relação as que receberam 
$70 \%$ de $\mathrm{N}\left(541 \mathrm{mg} \mathrm{dm}^{-3}\right)$ aos 145 DAE. O aumento da adubação com fertilizantes nitrogenandos podem levar a acidificação do meio, reduzindo a disponibilidade de nutrientes às plantas (CANTARELLA, 2007 e SOUSA et al., 2007).

Figura 2: Altura de planta - AP de porta-enxerto de goiabeira em função da salinidade da água de irrigação - CEa aos 70 e 145 dias após a emergência - DAE (A) e doses de nitrogênio aos 145 DAE (B).

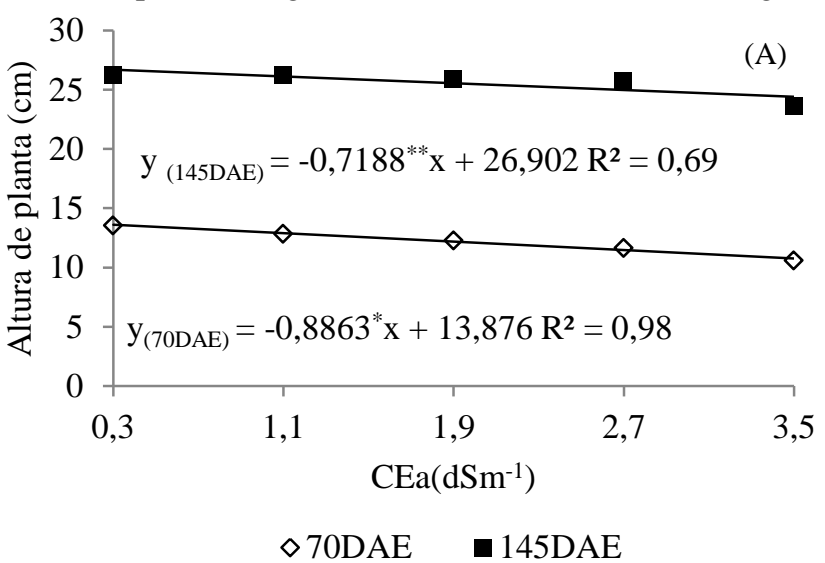

O número de folhas e área foliar de porta-enxerto de goiabeira forma afetados pelo aumento da CEa, onde aos 70 DAE apresentou efeito linear e decrescente de 5,14\% e 5,58\% respectivamente por aumento unitário da condutividade elétrica da água de irrigação (Figura 3A e 4A). As plantas submetidas à irrigação com a CEa de $3,5 \mathrm{dS} \mathrm{m}^{-1}$ sofreram reduções de 20,57\% (2,08 folhas por planta) e 18,72\% (17,79 $\mathrm{cm}^{2}$ ) em relação as plantas irrigadas com água de CEa de 0,3 $\mathrm{dS} \mathrm{m}{ }^{-1}$. Aos 145 DAE, observa-se efeito linear e decrescente para AF com aumento da CEa, ocorrendo reduções de 4,63\% por aumento unitário, ou seja, as plantas submetidas a CEa de $3,5 \mathrm{dS} \mathrm{m}^{-1}$ as perdas na AF foram de $38,20 \mathrm{~cm}^{2}(18,52 \%)$. De acordo com Oliveira et al. (2011) a redução no número de folhas e área foliar esta relacionada com modificações morfológicas e anatômicas, com o intuito de manter a absorção de água em ambientes salinos e uma forma de reduzir a transpiração.

$\mathrm{O}$ acúmulo de sais no solo pela irrigação com $\mathrm{CEa}$ elevada (concentração de $\mathrm{NaCl}$ ) contribuiu negativamente

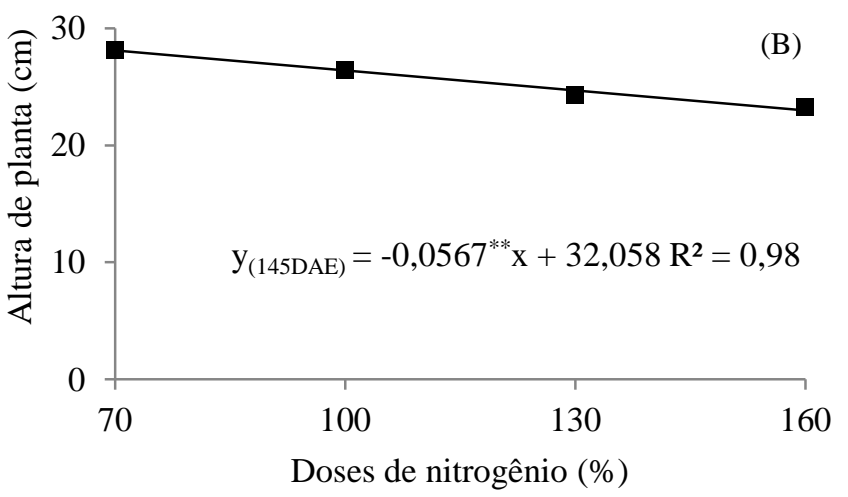

sobre a absorção de água pelas plantas, o que é determinante para a redução dos processos fotossintéticos e metabólicos das plantas, de forma a provocar redução da AP, DC e NF à medida em que CEa foi acrescida (TRAVASSOS et al., 2012).

A adubação nitrogenada nas doses de 70, 130 e 160\% de $\mathrm{N}$ promoveram efeito linear e decrescente sobre a NF aos 145 DAE onde, de acordo com as equações de regressão (Figura 3B), com o aumento da salinidade, as plantas que receberam a maior CEa $\left(3,5 \mathrm{dSm}^{-1}\right)$ sofreram decréscimos de 13,$12 ; 35,55$ e $43,10 \%$, respectivamente, quando comparadas com as plantas que receberam a menor salinidade $\left(0,3 \mathrm{dSm}^{-1}\right)$. A redução por aumento unitário da condutividade elétrica foi de $3,28 \%$ (dose $70 \%$ de N) 8,88\% (dose $130 \%$ de N) e $9,17 \%$ (dose $160 \%$ de N), não foi observado efeito significativo para dose de $100 \%$ de N. Em condições salinas é notória redução na absorção de nitrogênio pelas plantas, em consequência do efeito antagônico existente entre íons de nitrato e de cloro (ABD EL-SHAMAD et al., 2000).

Figura 3: Número de folhas - NF de porta-enxerto de goiabeira em função da salinidade da água de irrigação - CEa aos 70 dias após a emergência - DAE (A) e da interação entre salinidade da água de irrigação e adubação nitrogenada aos 145 DAE (B).
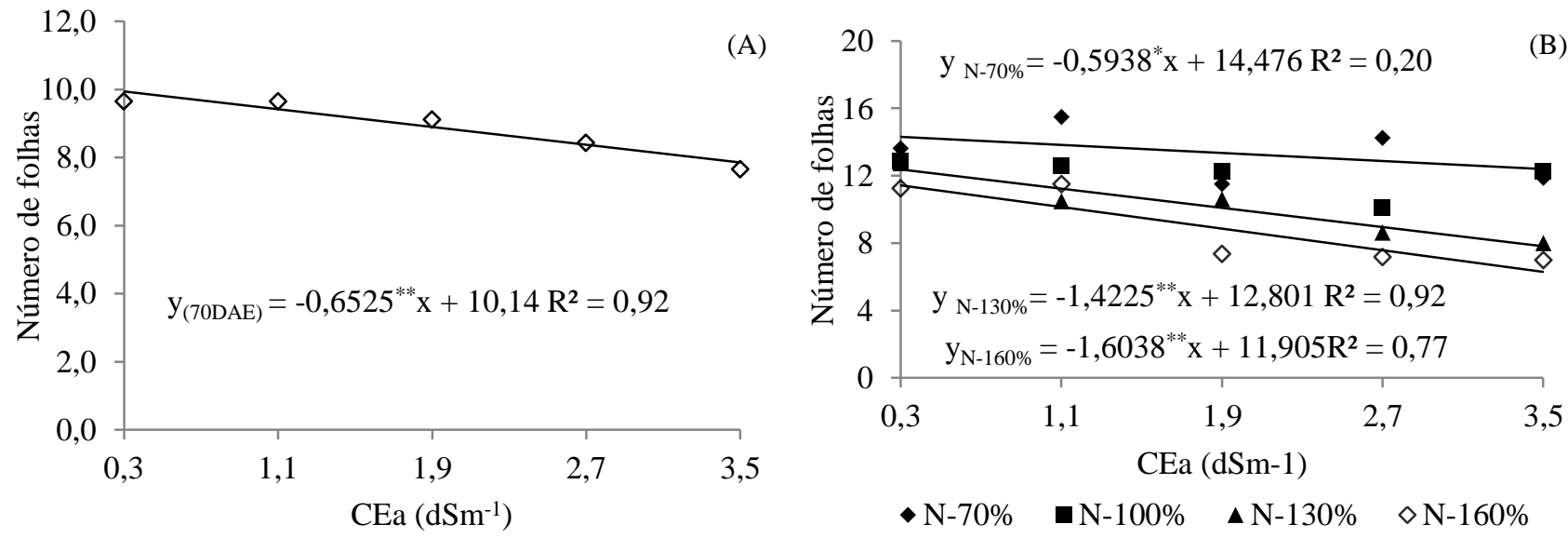
Figura 4: Área foliar - AP de porta-enxerto de goiabeira em função da salinidade da água de irrigação - CEa aos 70 e 145 dias após a emergência - DAE (A) e doses de nitrogênio aos 145 DAE (B).

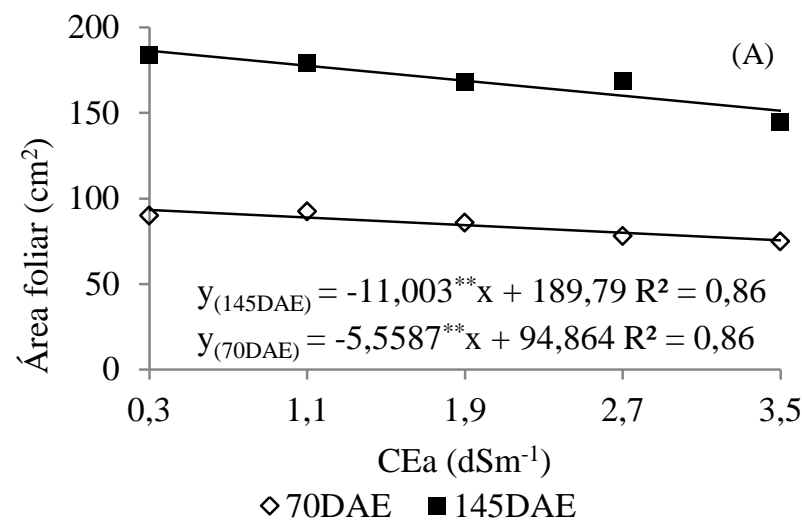

Conforme o resumo da análise de variância (Tabela 3) observa-se que houve efeito significativo $(\mathrm{p}<0,01)$ dos níveis salino da água de irrigação sobre razão de área foliar e taxa de crescimento relativo do diâmetro do caule (TCRdc) no

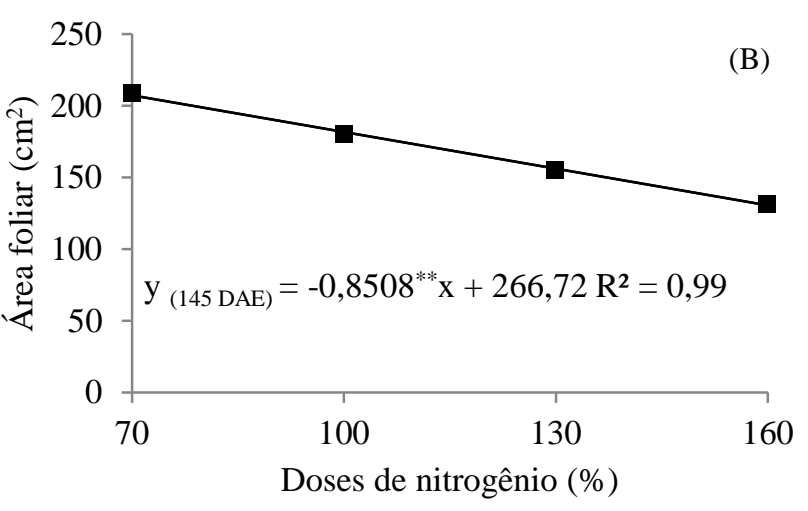

intervalo de 25 à 145 DAE. E para o fator dose de nitrogênio verifica-se apenas efeito significativo apenas para TCAdc. Não foi observada interação significativa entre os fatores salinidade da água de irrigação x doses de nitrogênio.

Tabela 3: Resumo da análise de variância para razão de área foliar (RAF), aos 190 dias após a emergência (DAE), taxa de crescimento absoluto (TCAdc) e relativo do diâmetro do caule (TCRdc) de porta-enxerto de goiabeira cv. Crioula irrigada com águas salinas e sob distintas doses de adubação nitrogenada, no intervalo de 25 à 145 DAE.

\begin{tabular}{lcccc}
\hline \multicolumn{1}{c}{ Fonte de variação } & GL & RAF & $\begin{array}{c}\text { Quadrado médio } \\
\text { TCAdc }\end{array}$ & TCRdc \\
\hline & & & $25-145$ & $25-145$ \\
\hline Níveis salinos (S) & 4 & $680,793^{* *}$ & $0,000122^{\mathrm{ns}}$ & $0,000009^{* *}$ \\
Reg. Linear & 1 & $2155,978^{* *}$ & $0,000078^{\mathrm{ns}}$ & $0,000001^{\mathrm{ns}}$ \\
Reg. Quadrática & 1 & $410,700^{*}$ & $0,000041^{\mathrm{ns}}$ & $0,000003^{\mathrm{ns}}$ \\
Doses de N (DN) & 3 & $99,310^{\mathrm{ns}}$ & $0,00007^{*}$ & $0,000004^{\mathrm{ns}}$ \\
Reg. Linear & 1 & $30,184^{\mathrm{ns}}$ & $0,0001^{* *}$ & $0,000007^{\mathrm{ns}}$ \\
Reg. Quadrática & 1 & $0,00004^{\mathrm{ns}}$ & $0,00003^{\mathrm{ns}}$ & $0,000003^{\mathrm{ns}}$ \\
Interação S*DN & 12 & $116,782^{\mathrm{ns}}$ & $0,00004^{\mathrm{ns}}$ & $0,000005^{\mathrm{ns}}$ \\
Blocos & 3 & $229,534^{\mathrm{ns}}$ & $0,00001^{\mathrm{ns}}$ & $9,833^{\mathrm{ns}}$ \\
CV $(\%)$ & & $19,82^{2}$ & 37,96 & 34,77 \\
\hline
\end{tabular}

ns, **, * respectivamente não significativos, significativo a $\mathrm{p}<0,01$ e $\mathrm{p}<0,05$;

De acordo com a equação de regressão (Figura 5) observa-se que houve efeito linear crescente dos níveis de CEa sobre RAF, com redução de $11,54 \%$ por aumento unitário na $\mathrm{CEa}$, ao $190 \mathrm{DAE}$.

Figura 5: Razão de área foliar - RAF de porta-enxerto de goiabeira em função da salinidade da água de irrigação - CEa aos 190 dias após a emergência - DAE

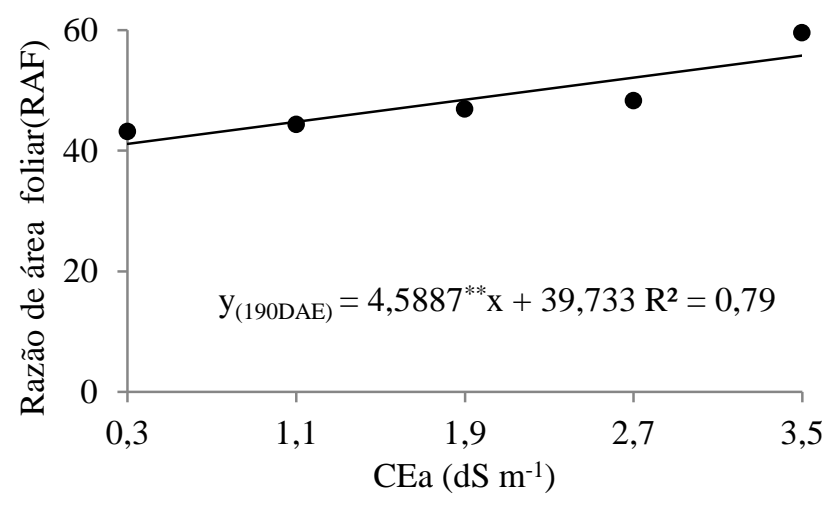

A TCAdc foi afetada pela adubação nitrogenada e de acordo com a equação de regressão (Figura 6), houve efeito linear decrescente de $8,10 \%$, para cada incremento de $30 \%$ na dose de $\mathrm{N}$. A dinâmica natural do $\mathrm{N}$ e a perda deste no sistema solo-planta criam um desafio único para seu correto manejo, pois elevados teores de $\mathrm{N}$ podem proporcionar desbalanço nutricional no solo e, em consequência, afetar o crescimento e produção da cultura (OLIVEIRA et al., 2009).

Figura 6: Taxa de crescimento absoluto do diâmetro do caule - (TCAdc) de porta-enxerto de goiabeira em função de doses de nitrogênio no período de 25 à 145 DAE.

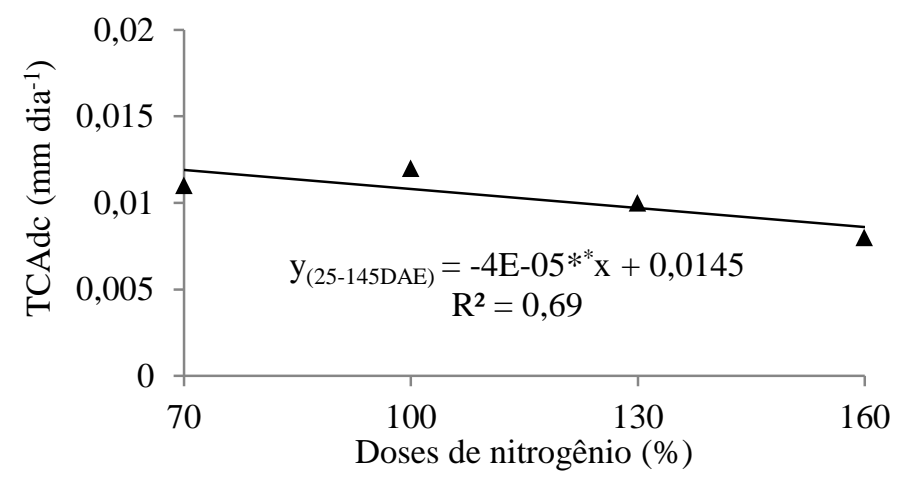




\section{CONCLUSÕES}

A dose de $70 \%$ de $\mathrm{N}\left(541,1 \mathrm{mg}\right.$ de $\mathrm{N} \mathrm{dm}^{-1}$ de solo) proporciona maior diâmetro de caule de porta-enxerto de goiabeira "Crioula" aos 70 e 145 dias após a emergência (DAE), maior área foliar e altura de planta aos 145 DAE e, taxa de crescimento absoluto diâmetro do caule dos 25 a 145 DAE.

A irrigação com água de salinidade acima de $0,3 \mathrm{dS} \mathrm{m}^{-1}$ afeta positivamente a razão de área foliar e, de forma negativa, o número de folhas, a área foliar e o diâmetro do caule.

Houve interação entre os fatores salinidade da água de irrigação e adubação nitrogenada para o número de folhas de porta-enxerto de goiabeira "Crioula" aos 145 DAE.

\section{REFERÊNCIAS BIBLIOGRÁFICAS}

ABD EL-SHAMAD, H.M.; SHADDAD, M.A.K. Comparative effect of sodium carbonate, sodium sulfate, and sodium chloride on the growth and related metabolic activities of plants. Journal Plant Nutrition, v.19, n.5, p.717-728, 2000

ASHRAF M.; HARRIS, P.J.C. Potential biochemical indicators of salinity tolerance in plants. Plant Science, v.166, n.1, p.3-16, 2004.

BENINCASA, M. M. P. Análise de crescimento de plantas, noções básicas. 2 ed. Jaboticabal: FUNEP, 2003. 41 p.

CANTARELla, H. Nitrogênio. In: NOVAES, R. F.; ALVAREZ V, V. H.; BARROS, N. F.; FONTES, R. L. F.; CANTARUTTI, R. B.; NEVES, J. C. L. Fertilidade do solo. 1 ed., Viçosa: SBCS, 2007. 1017 p

CAVALCANTE, Í. H. L.; CAVALCANTE, L. F.; HU, Y.; BECKMANN-CAVALCANTE, M. Z. Water salinity and initial development of four guava (Psidium guajava L.) cultivar in north-eastern Brazil. Journal of Fruit and Ornamental Plant Research, v. 15, p. 71-80, 2007.

CLAESSEN, M. E. C. (org.). Manual de métodos de análise de solo. 2.ed. Rio de Janeiro: EmbrapaCNPS, 1997. 212p. Documentos, 1

DIAS, M. J. T.; SOUZA, H. A.; NATALE, W.; MODESTO, V. C.; ROZANE, D. E. Adubação com nitrogênio e potássio em mudas de goiabeira em viveiro comercial. Ciências Agrárias, v. 33, p. 2837-2848, 2012.

FERNANDES, P.D.; GHEYI, H. R.; ANDRADE, E. P.; MEDEIROS, S. S. Biossalinidade e produção agrícola. In: GHEYI, H. R.; DIAS, N. S.; LACERDA, C. F. Manejo da salinidade na agricultura. Fortaleza, INCT Sal, 2010. 472p.

FERREIRA, P. A.; GARCIA, G. O.; NEVES, J. C. L.; MIRANDA, G. V.; SANTOS, D. B. Produção relativa do milho e teores folheares de nitrogênio, fósforo, enxofre e cloro em função da salinidade do solo. Revista Ciência Agronômica, v.38, n.1, p.7-16, 2007.
FRANCO, F. C. et al. Curva de crescimento e marcha de absorção de macronutrientes em mudas de goiabeira. Revista Brasileira de Ciência do Solo, Viçosa, v. 31, n. 6, p. 1429-1437, 2007.

FREIRE, A. L. de O; SARAIVA, V. P; MIRANDA, J. R. P. de; BRUNO, G. B. Crescimento, acúmulo de íons e produção de tomateiro irrigado com água salina. Semina: Ciências Agrárias, Londrina, v. 31, suplemento 1, p. 1133-1144, 2010

FREITAS, B. M.; ALVES, J. E. Efeito do número de visitas fl orais da abelha melífera (Apis mellifera L.) na polinização da goiabeira (Psidium guajava L.) cv. Paluma, Revista Ciência Agronômica, Fortaleza, v. 39, n. 01, p. 148-154, 2008.

GURGEL, M. T. et al. Estresse salino na germinação e formação de porta-enxerto de aceroleira. Revista Brasileira de Engenharia Agrícola e Ambiental, Campina Grande, v.7, n.1, p.31-36, 2003.

INSTITUTO BRASILEIRO DE GEOGRAFIA E ESTATÍSTICA-IBGE. Produção agrícola municipal, Rio de Janeiro, v. 39, p.1-101, 2012.

LIMA, L. G. S.; ANDRADE, A. C.; SILVA, R. T. L.; FRONZA, D.; NISHIJIMA, T. Modelos matemáticos para estimativa de área foliar de goiabeira (Psidiumguajava L.). In: Reunião Anual da SBPC, 64,São Luiz: UFMA, 2012.

MEDEIROS, J. F de. Qualidade de água de irrigação e evolução da salinidade nas propriedades assistidas pelo GAT nos Estados de RN, PB e CE. Campina Grande:Universidade Federal da Paraíba, 1992.173p. Dissertação Mestrado

MENDONÇA, V. Cultura da goiaba. Mossoró: UFERSA, 2011. 40 p. (Boletim técnico).

MUNNS, R. Genes and salt tolerance: bringing them together. New Phytologist, v.167, p.645-663, 2005.

NEVES, A.L.R.; LACERDA, C.F. de; GUIMARÃES, F.V.A.; HERNANDEZ, F.F.F.; SILVA, F.B.; PRISCO, J.T. \& GHEYI, H.R. Acumulação de biomassa e extração de nutrientes por plantas de feijão-de-corda irrigadas com água salina em diferentes estádios de desenvolvimento. Ciência Rural, v.39, n.3, p. 758-765, 2009.

OLIVEIRA, F. A.; CARRILHO, M. J. S. O.; MEDEIROS, J. F.; MARACAJÁ, P. B.; OLIVEIRA, M. K. T. Desempenho de cultivares de alface submetidas a diferentes níveis de salinidade da água de irrigação. Revista Brasileira de Engenharia Agrícola e Ambiental, v.15, n.8, p.771-777, 2011.

OLIVEIRA, F. T. DE; HAFLE, O. M.; MENDONÇA, V.; MOREIRA, J. N.; PEREIRA JÚNIOR, E. B.; ROLIM, H. O. Respostas de porta-enxertos de goiabeira sob diferentes fontes e proporções de materiais orgânicos.Comunicata Scientiae, v.6, p.17-25, 2015. 
OLIVEIRA, F.A. de; OLIVEIRA FILHO, A.F. de; MEDEIROS, J.F. de; ALMEIDA JUNIOR, A.B.; LINHARES, P.C.F. Desenvolvimento inicial da mamoneira sob diferentes fontes e doses de matéria orgânica. Revista Caatinga, v.22, n.1, p. 206- 211, 2009

QUEIROZ, J. E.; GONÇALVES, A. C. A.; SOUTO, J. S.; FOLEGATTI, M. V. Avaliação e monitoramento da salinidade do solo. In: GHEYI, R. H.; DIAS, N. S.; LACERDA, C.F. Manejo da salinidade na agricultura: Estudos básicos e aplicados. Fortaleza: INCT, 2010. $472 \mathrm{p}$.

RHOADES, J. D.; KANDIAH, A.; MASHALI, A. M. Uso de águas salinas para 204 produção agrícola. UFPB, 2000, 117p. Estudos da FAO, Irrigação e Drenagem, 48, 205 revisado.

SOUSA, D. M. G.; MIRANDA, L. N.; OLIVEIRA, S. A. Acidez do solo e sua correção. In: NOVAES, R. F.; ALVAREZ V, V. H.; BARROS, N. F.; FONTES, R. L. F.; CANTARUTTI, R. B.; NEVES, J. C. L. Fertilidade do solo. 1 ed., Viçosa: SBCS, 2007. 1017 p.

TRAVASSOS, K. D; GHEYI, H. R; SOARES, F. A. L; BARROS, H. M. M; SILVA, N. da. DIAS4; UYEDA, C. A; SILVA, F. V. da. Crescimento e desenvolvimento de variedades de girassol irrigado com água salina. Irriga, Botucatu, Edição Especial, p. 324 - 339, 2012.

WILLADINO, L.; CAMARA, T. R. Origen y naturaleza de los ambientes salinos. In: Reigosa, M.J.; Pedrol, N.; Sánchez, A. (eds). La Ecofisiología Vegetal - Uma ciencia de síntesis. Madrid. Thomson. 2004. cap. 10, p. 303-330. 